\title{
ELECTROPHYSIOLOGICAL INVESTIGATIONS ON THE EFFECT OF REPEATED ZIMELIDINE ADMINISTRATION ON SEROTONERGIC NEUROTRANSMISSION IN THE RAT ${ }^{1}$
}

\author{
PIERRE BLIER AND CLAUDE DE MONTIGNY ${ }^{2}$
}

Centre de Recherche en Sciences Neurologiques, Faculté de Médecine, Université de Montréal, Case postale 6128, Succursale A, Montréal, Québec, Canada H3C $3 J 7$

Received August 18, 1982; Revised December 15, 1982; Accepted January 28, 1983

\begin{abstract}
Zimelidine, a selective serotonergic (5-H'T) reuptake blocker, is a clinically effective antidepressant. However, its rapid action on reuptake is in apparent discrepancy with its delayed clinical efficacy, and data on the effect of its chronic administration on 5-HT neurotransmission have never been provided.

In the first series of experiments, the response of $\mathrm{CA}_{3}$ hippocampus pyramidal neurons to the electrical stimulation of the ventromedial ascending 5-HT pathway was assessed from peristimulus time histograms, and the responsiveness of the same cells to iontophoretic applications of 5-HT and $\gamma$-aminobutyric acid (GABA) was measured using the $I \cdot T_{50}$ method. The suppression of firing of pyramidal neurons induced by the stimulation was significantly greater in zimelidine-treated rats ( $5 \mathrm{mg} / \mathrm{kg}$, i.p., q.d. for 14 days) than in controls, but the $\mathrm{I} \cdot \mathrm{T}_{50}$ for $5-\mathrm{HT}$ and GABA was not modified by the zimelidine treatment.

In a second series of experiments, unitary recordings of 5-HT neurons were obtained from the mesencephalic dorsal raphe nucleus. After 2 days of zimelidine treatment $(5 \mathrm{mg} / \mathrm{kg}$, i.p., q.d.), the number of 5-HT units discharging spontaneously was greatly reduced. After 7 days of treatment, the number of active 5-HT neurons had returned to normal values, but their firing rate was slower than in control animals. After a treatment of 14 days, both the number of active 5-HT units and their mean firing rate were within normal range. At this time, the responsiveness of 5-HT neurons to intravenous lysergic acid diethylamide (LSD) was assessed: the $\mathrm{ED}_{50}$ of LSD was 2- to 3-fold greater than in control rats, indicating that their autoreceptors had desensitized.

It is concluded that long-term zimelidine treatment enhances the efficacy of 5-HT neurotransmission in the hippocampus. However, the reuptake blockade by zimelidine cannot result in an enhanced 5-HT neurotransmission until 5-HT neurons resume a normal electrical activity. This sequence of events may well account for the delayed antidepressant effect of zimelidine in major depression.
\end{abstract}

Serotonin (5-HT) has long been thought to be implicated in the clinical effect of antidepressant treatments (Lapin and Oxenkrüg, 1969). By means of microiontophoresis, several groups of investigators have evidenced a sensitization of rat forebrain neurons to 5-HT following chronic administration of different types of tricyclic antidepressant (TCA) drugs (De Montigny and Aghajanian,

\footnotetext{
${ }^{1}$ We thank D. Tardif for technical assistance, D. Cyr and G. B. Filosi for preparing the illustrations, $M$. Lerebours for typing the manuscript, and $\mathrm{G}$. Blanchette and S. Rossignol for making available the computer analyses. This research was supported, in part, by Canadian Medical Research Council Grant MA-6444. C. De M. is a recipient of a scholarship from the Fonds de la Recherche en Santé du Québec.

${ }^{2}$ To whom correspondence should be addressed.
}

1978; Gallagher and Bunney, 1979; Menkes et al., 1980; Wang and Aghajanian, 1980; De Montigny et al., 1981a; Menkes and Aghajanian, 1981). This sensitization has a time course consistent with the delayed clinical effect of these drugs and is obtained with doses falling in the range of clinical dosage. Furthermore, it seems to be specific to this class of drugs. These observations suggest that this sensitization to 5-HT might be implicated in the therapeutic effect of these drugs. This hypothesis is in keeping with the reversal of the therapeutic effect of imipramine by the administration of a 5-HT synthesis inhibitor (Shopsin et al., 75).

Chronic electroconvulsive shock treatment has been shown to enhance the behavioral response to 5-HT agonists in rats (Fvans et al., 1976; Green et al., 1977; 
Grahame-Smith et al., 1978; Costain et al., 1979) and to induce an enhanced responsiveness of forebrain neurons to microiontophoretically applied 5-HT (De Montigny, 1980). Thus, two very different types of treatments, TCA drugs and electroconvulsive shock treatment, both effective in major depression, share this neurobiological effect. This further suggests that enhancing 5-HT neurotransmission might have an antidepressant effect in major depression.

The addition of lithium to the therapeutic regimens of patients presenting a major depression treated with but not responding to a TCA drug brings a rapid and profound amelioration of depression in most cases (De Montigny et al., 1981b; Heninger and Charney, 1982). Given the enhancement of the activity of $5-\mathrm{HT}$ neurons by short-term lithium (Grahame-Smith and Green, 1974), this clinical phenomenon might be due to an amplification of the effect of lithium on the 5-HT system by the TCA-induced sensitization of postsynaptic neurons.

Zimelidine is a selective 5-HT reuptake blocker (Ross and Renyi, 1977) and a clinically effective antidepressant (Aberg and Holmberg, 1979; Coppen et al., 1979; Montgomery et al., 1981; Gershon et al., 1982). Its demethylated metabolite, norzimelidine, is an even more potent 5-HT reuptake blocker (Ross and Renyi, 1977). However, the rapid action of zimelidine on 5-HT reuptake was in apparent discrepancy with its delayed clinical efficacy (Montgomery et al., 1981; Gershon et al., 1982). Furthermore, the net effect of its chronic administration on 5HT neurotransmission has never been documented.

In order to assess the net effect of zimelidine treatment on 5-HT neurotransmission, four aspects of the functioning of the 5-HT system were investigated electrophysiologically in the present study: (1) the responsiveness of forebrain neurons to microiontophoretically applied 5$\mathrm{HT}$; (2) the response of the same neurons to electrical stimulation of the ascending 5-HT pathway; (3) the activity of the 5-HT neurons; and (4) the sensitivity of the 5-HT autoreceptor.

\section{Materials and Methods}

Experiments on postsynaptic neurons. Ten male Sprague-Dawley rats (150 to $250 \mathrm{gm}$ ) were treated for 14 days with daily injections of zimelidine $(5 \mathrm{mg} / \mathrm{kg}$, i.p.). Twenty-four hours after the last injection, rats were anesthetized with chloral hydrate $(400 \mathrm{mg} / \mathrm{kg}$, i.p.) and mounted in a stereotaxic apparatus. Five-barrelled glass micropipettes were prepared in a conventional manner (Haigler and Aghajanian, 1974). The central barrel used for recording was filled with a $2 \mathrm{M} \mathrm{NaCl}$ solution saturated with Fast Green FCF and the side barrels were filled with the following solutions: 5-HT creatinine sulfate ( 2 or $0.5 \mathrm{~mm}$ in $200 \mathrm{~mm} \mathrm{NaCl}, \mathrm{pH} 4$; Regis), $\gamma$-aminobutyric acid (GABA) (50 mM in $50 \mathrm{~mm} \mathrm{NaCl}, \mathrm{pH} \mathrm{4}$; Calbiochem) and acetylcholine chloride (ACh) $(20 \mathrm{~mm}$ in 200 $\mathrm{mm} \mathrm{NaCl}, \mathrm{pH} 4.0$; Calbiochem), and $\mathrm{NaCl}(2 \mathrm{M})$. This latter barrel was used for automatic current balancing. $\mathrm{CA}_{3}$ hippocampal pyramidal neurons were identified by their large amplitude ( 0.5 to $1.2 \mathrm{mV}$ ) and long duration ( 0.8 to $1.2 \mathrm{msec}$ ) action potentials, and their characteristic complex spike discharge, alternating with simple spike activity (Kandel and Spencer, 1961). Fast Green was deposited at the last recording site with $\mathrm{a}-26 \mu \mathrm{A}$ current for subsequent histological verification. Since most hippocampal pyramidal neurons are not spontaneously active in chloral hydrate-anesthetized rats, a small current of $\mathrm{ACh}$ was used to obtain a firing rate in the physiological range ( 8 to $12 \mathrm{~Hz}$ ). The mean currents of ACh used in controls and zimelidine-treated rats were similar $(3.7 \pm 0.6$ and $3.3 \pm 0.4 \mathrm{nA}$, respectively). The neuronal responsiveness to microiontophoretic applications was assessed using the previously described $\mathrm{I} \cdot \mathrm{T}_{50}$ method (De Montigny and Aghajanian, 1977). Briefly, neuronal sensitivity is estimated from the charge (current $\mathrm{I}$ in $\mathrm{nA}$ by time $\mathrm{T}_{50}$ in seconds) required to obtain a $50 \%$ depression of firing rate from base line.

A bipolar concentric electrode (NE-100, David Kopf Instruments) was positioned on the midline at a backward angle of $10^{\circ}$ in the ventromedial tegmentum (VMT) at $\mathrm{A}=2.0 ; \mathrm{V}=2.3$ according to König and Klippel (1963). At the end of each experiment a current of $0.5 \mathrm{~mA}$ was passed for $10 \mathrm{sec}$ through the stimulating electrode to make a lesion. 'This permitted the subsequent localization of the electrode tip from histological sections (Fig. 1). Square pulses of $0.5 \mathrm{msec}$ were delivered at $0.8 \mathrm{~Hz}$ with intensities of $40,80,160$, and $300 \mu \mathrm{A}$. Pulses were generated by a Grass S8 stimulator and were delivered through a direct-coupled isolation unit (model SIV478A). The unitary activity was recorded on magnetic tapes and subsequently was analyzed on a PDP-11 computer. Peristimulus time histograms of hippocampal cell firing were generated to measure the period of suppression of firing.

Raphe neuron recordings. Given that both dorsal and medial raphe nuclei send 5-HT projections to the hippocampus (Köhler, 1982; Köhler and Steinbusch, 1982) and that the properties of these two populations of 5-HT neurons are similar (Aghajanian and Haigler, 1974), recordings were obtained from the dorsal raphe nucleus where the density of 5-HT neurons is greater and thus lends itself more readily to a systematic investigation.

Twelve rats received daily injections of zimelidine (5 $\mathrm{mg} / \mathrm{kg}$, i.p.) for 2,7 , or 14 days. Twenty-four hours after the last injection, they were anesthetized with chloral hydrate $(400 \mathrm{mg} / \mathrm{kg}$, i.p.) and mounted in a stereotaxic apparatus. 5-HT raphe neurons were recorded using single-barrelled glass micropipettes filled with a $2 \mathrm{M} \mathrm{NaCl}$ solution saturated with Fast Green. Theta micropipettes with one barrel filled with glutamate ( $0.1 \mathrm{M}, \mathrm{pH} 8$; Sigma) were used to activate silent 5-HT neurons in the 2-day pretreatment group. 5-HT neurons were identified using the criteria established by Aghajanian (1978): a slow (0.5 to $2.5 \mathrm{~Hz})$ and regular firing rate, a long duration $(0.8$ to $1.2 \mathrm{msec}$ ), and positive action potential. The electrode was first lowered at $0.8 \mathrm{~mm}$ anterior to lambda on midline, and four other trajectories were performed $200 \mu \mathrm{m}$ anterior, $200 \mu \mathrm{m}$ posterior, and $200 \mu \mathrm{m}$ on each side. The electrode descent was terminated $1 \mathrm{~mm}$ below the ventral border of the Sylvian aqueduct (Fig. 5A). Each 5-HT neuron encountered was recorded for at least $1 \mathrm{~min}$ to establish its basal firing rate. At the end of the experiment in control and 14-day pretreated animals, $10 \mu \mathrm{g} / \mathrm{kg}$ of lysergic acid diethylamide (LSD) (see Fig. 7) were 


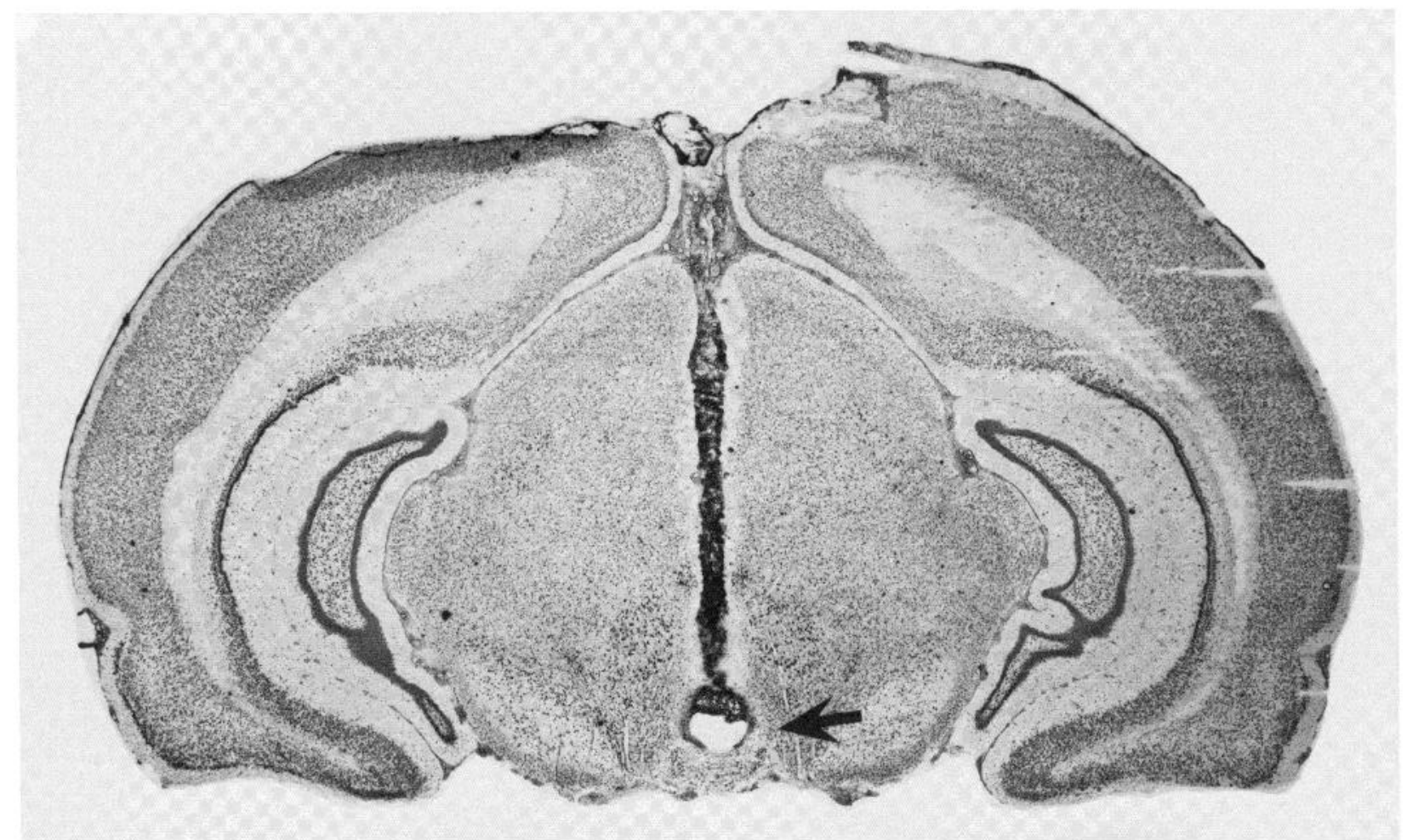

Figure 1. Histological section of the mesencephalon (at approximately A = 1.8 according to König and Klippel (1963)) showing a lesion made at the tip of the stimulating electrode (arrow). This lesion is in the VMT in which the ascending 5-HT bundle travels (Andén et al., 1966). It is noteworthy that in three rats where the tip of the stimulating electrode was outside of this region, there was no response to the electrical stimulation even at the highest intensity $(300 \mu \mathrm{A})$.

injected in a tail vein while a recording was made from a dorsal raphe 5-HT neuron exhibiting a stable firing rate. A Fast Green deposit was left at the bottom of the last electrode track and a mesencephalic block was cut for subsequent histological verification of the area of recording.

Experiments in 5-HT-denervated animals. 5,7-Dihydroxytryptamine (5,7-DHT; $200 \mu \mathrm{g}$ free base in $20 \mu \mathrm{l}$ of a $0.9 \% \mathrm{NaCl}$ and $0.1 \%$ ascorbic acid solution) was injected in the lateral ventricule in rats under chloral hydrate anesthesia to destroy the 5-HT neurons (Baumgarten and Lachenmayer, 1972). Thirty minutes before the administration of 5,7-DHT, desipramine hydrochloride (25 $\mathrm{mg} / \mathrm{kg}$; Merrell) was injected intraperitoneally to protect the noradrenergic system (Bjorklund et al., 1975; Gerson and Baldessarini, 1975). Two weeks after the denervation, systematic electrode tracks were done in the dorsal raphe, and the response of the $\mathrm{CA}_{3}$ pyramidal neurons to VMT stimulation was assessed as previously described. The destruction of 5-HT neurons was subsequently confirmed by histofluorescence.

\section{Results}

Responsiveness of $\mathrm{CA}_{3}$ pyramidal neurons to microiontophoretic applications of 5-HT. The 14-day pretreatment with zimelidine $(5 \mathrm{mg} / \mathrm{kg}$, i.p.) did not modify the responsiveness of $\mathrm{CA}_{3}$ hippocampal pyramidal neurons to microiontophoretically applied 5-HT as measured by the I. $T_{50}$ method (Fig. 2, Table I). Neither was the responsiveness of the same neurons to GABA modified.
This absence of any down- or up-regulation of responsiveness to 5 -HT by zimelidine pretreatment confirms an earlier report from our laboratory (De Montigny et al., 1981a).

Responsiveness of $\mathrm{CA}_{3}$ pyramidal neurons to electrical stimulation of the ascending 5-HT pathway. Responses to the electrical stimulation of the ascending 5HT pathway in the VMT were measured from the same neurons tested microiontophoretically in control and zimelidine-pretreated rats. The latency from the stimulation to the onset of suppression ranged from 4 to $12 \mathrm{msec}$. The peristimulus time histogram of Figure $3 B$ shows latencies of $6 \mathrm{msec}$. Given the distance of approximately $6 \mathrm{~mm}$ travelled by the impulse, these latencies indicate a conduction velocity of 0.5 to $1.5 \mathrm{~m} / \mathrm{sec}$. This is fully consistent with the slow conduction velocity of the small unmyelinated 5-HT fibers. Moreover, the marked reduction of the effect of VMT stimulation in 5,7-DHT-pretreated animals (Fig. 4) is a further indication that the effect of the VMT stimulation on $\mathrm{CA}_{3}$ pyramidal neurons is mediated by 5 -HT axons.

The 40- $\mu$ A stimulations had no detectable effect on the probability of firing of $\mathrm{CA}_{3}$ hippocampal neurons in both groups (Fig. 4). With an $80-\mu \mathrm{A}$ current, the mean duration of suppression of firing was longer in zimelidine-pretreated rats, but this difference failed to reach statistical significance due to the wide variation of the responses (Fig. 4). More constant effects were produced by stimulations of $160 \mu \mathrm{A}$. Figure 3 shows the effect of $160-\mu \mathrm{A}$ stimulations in a control animal $(A)$ and a zimelidine- 
pretreated animal $(B)$ : there was no effect in the control rat, whereas a 20 -msec reduction of the firing probability was obtained in the zimelidine-pretreated rat. At $300 \mu \mathrm{A}$, the period of suppression was also longer in the zimelidine

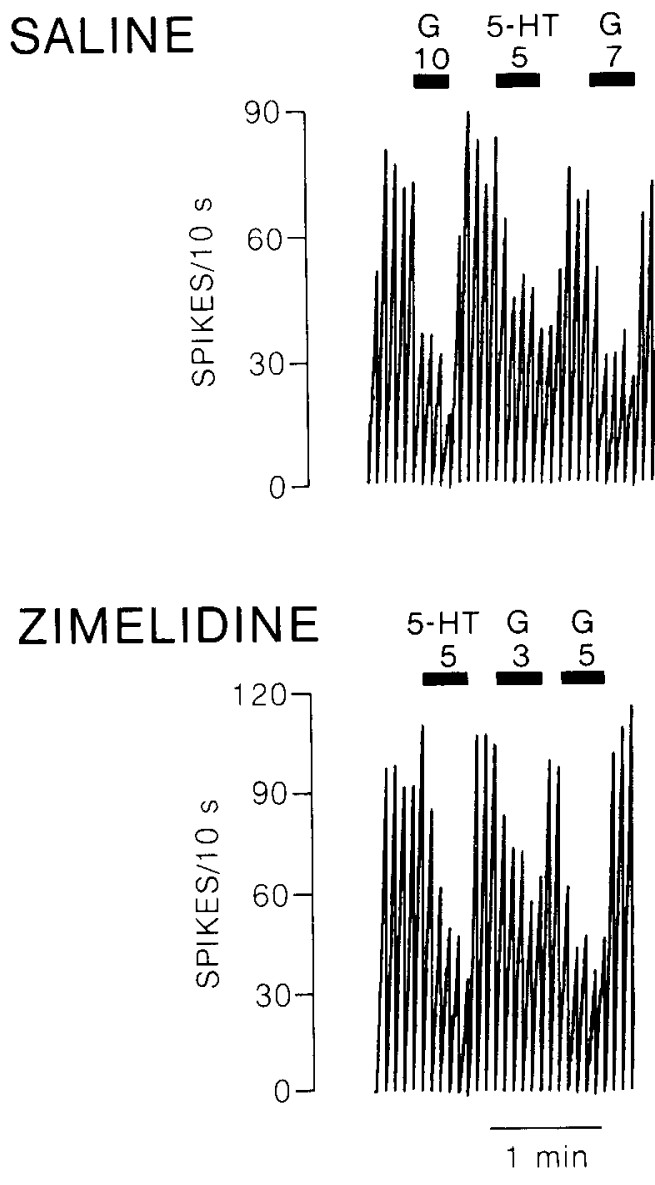

Figure 2. Histograms of the integrated firing rate of pyramidal hippocampal neurons recorded in the $\mathrm{CA}_{3}$ region of a control and a zimelidine-pretreated rat $(5 \mathrm{mg} / \mathrm{kg}$, i.p., q.d. $\times 14$ days) showing the responses of these neurons to microiontophoretic applications of 5-HT and GABA (G). Solid bars indicate the duration of applications; current is given in nanoamperes; the time base applies to both traces. group (Fig. 4); however, it was more difficult to assess precisely the duration of the inhibitory effect of the stimulation since, in many cells, the period of suppression was followed by an increased probability of firing.

These results show that the response of the postsynaptic element to the electrical stimulation of the ascending 5 -HT pathway is augmented by chronic zimelidine administration, whereas the responsiveness of the same postsynaptic neurons to microiontophoretically applied 5-HT was not modified. Hence, the enhanced effect of the activation of the 5-HT pathway under zimelidine must be due to a presynaptic modification, most probably to the impairment of the 5-HT reuptake process.

Firing rate of 5-HT neurons. If 5-HT reuptake blockade were responsible for the antidepressant effect of zimelidine, it could be expected to exert its antidepressant effect rapidly. However, zimelidine, like TCA drugs, requires a long-term administration before a full antidepressant effect is obtained (Montgomery et al., 1981; Gershon et al., 1982). How can this delayed clinical action be reconciled with the rapid blockade of 5-HT reuptake? Since the rate of firing of 5-HT neurons is a critical factor for the release of the neurotransmitter (Aghajanian et al., 1975), we studied the activity of 5-HT neurons in the dorsal mesencephalic raphe nucleus during the course of zimelidine treatment.

In control rats, a mean number of $4.2 \pm 0.65-\mathrm{HT}$ neurons was recorded per 1-mm electrode track (see Fig.

TABLE I

Responsiveness of $\mathrm{CA}_{3}$ hippocampal pyramidal neurons to microiontophoretic applications of 5-HT and GABA in control and zimelidine-treated rats $^{a}$

\begin{tabular}{ccc}
\hline & Control & Zimelidine \\
\hline 5 -HT & $168 \pm 11$ & $185 \pm 11$ \\
& $(28)^{b}$ & $(33)$ \\
GABA & $200 \pm 35$ & $169 \pm 24$ \\
& $(15)$ & $(17)$
\end{tabular}

${ }^{a}$ Zimelidine was administered at a daily dose of $5 \mathrm{mg} / \mathrm{kg}$, i.p., for 14 days; values are expressed as mean $\mathrm{I} \cdot \mathrm{T}_{50} \pm \mathrm{SEM}$. $\mathrm{I} \cdot \mathrm{T}_{50}$ values for 5 $\mathrm{HT}$ and GABA in zimelidine-pretreated rats were not significantly different $(p>0.05)$ from control values.

${ }^{b}$ Numbers in parentheses, number of units tested.
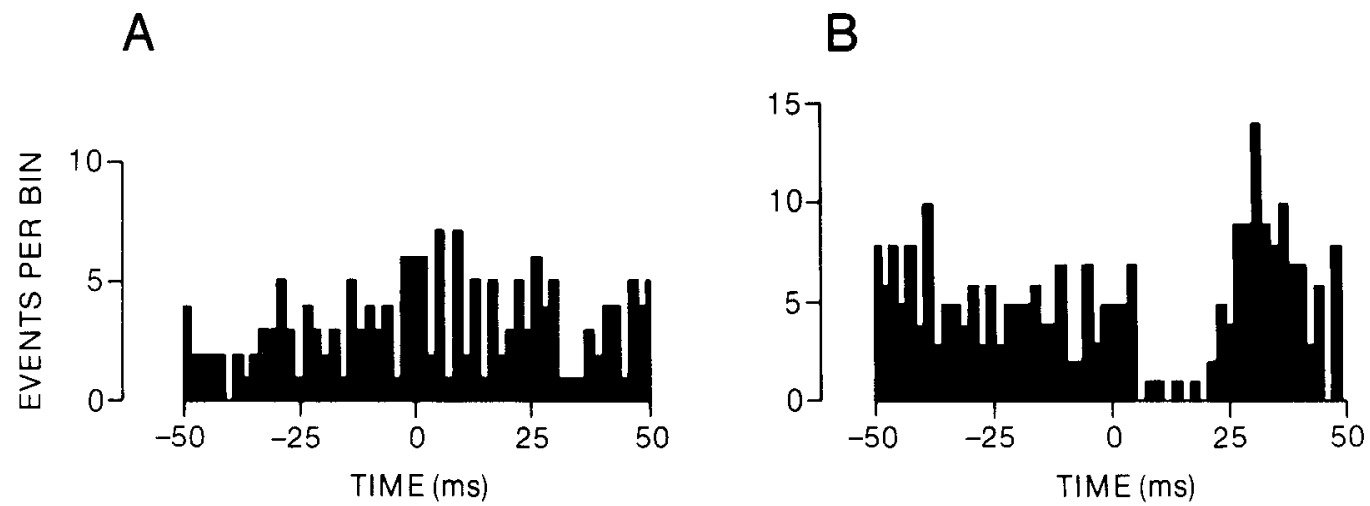

Figure 3. Peristimulus time histograms of $\mathrm{CA}_{3}$ hippocampal pyramidal neurons recorded in a control rat $(A)$ and in a rat treated with zimelidine ( $5 \mathrm{mg} / \mathrm{kg}$, i.p., q.d. $\times 14$ days) $(B)$. Each histogram was constructed from 150 stimuli of $0.5 \mathrm{msec}$ delivered at $0.8 \mathrm{~Hz}$ with an intensity of $160 \mu \mathrm{A}$ in the VMT. Bin width is 2 msec, the total observation period being 100 msec. The stimulation pulse was delivered at time 0 . 


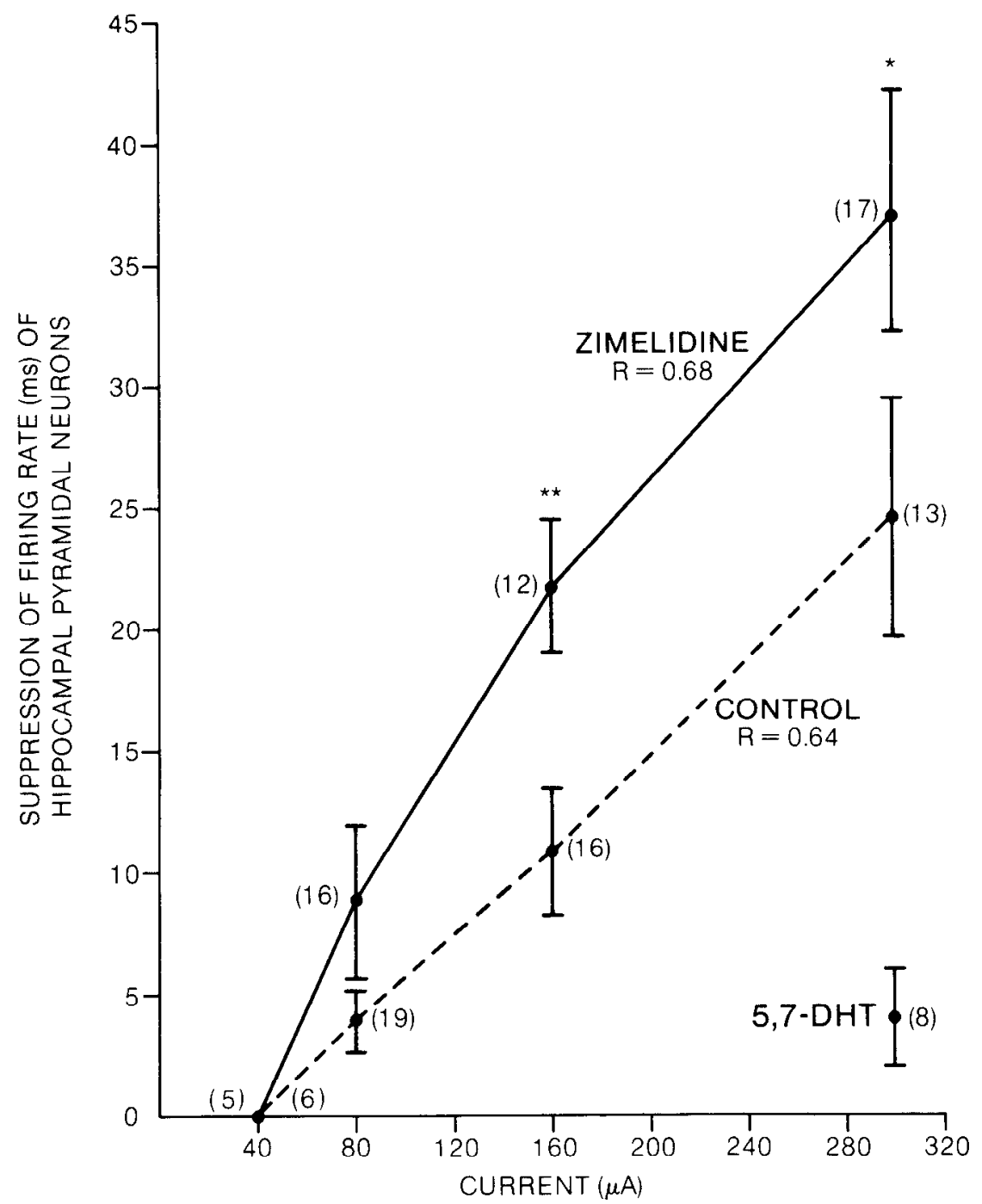

Figure 4. Relationship between the duration of suppression of $\mathrm{CA}_{3}$ hippocampal pyramidal neuron firing and the intensity of the current used to stimulate the ascending 5-HT pathway in control and zimelidine-pretreated rats $(5 \mathrm{mg} / \mathrm{kg}$, i.p., q.d. $\times 14$ days $)$. Values are expressed as means $\pm \mathrm{SEM}$; the number of cells tested is indicated in parentheses. $*, p<0.05 ; * *, p<0.001$ (Student's $t$ test, comparing control and zimelidine groups).

$5 A$ ); their mean firing rate was $1.2 \pm 0.1 \mathrm{~Hz}$ (Fig. 6). Using the same procedure, no 5-HT neurons were recorded in 5,7-DHT-denervated animals. This is consistent with the total disappearance of 5-HT somata in the dorsal raphe in sections prepared for histofluorescence. Twenty-four hours after a 2-day treatment with zimelidine ( $5 \mathrm{mg} / \mathrm{kg}$, i.p., q.d.), hardly any 5 -HT neurons were discharging spontaneously (Table II). When probing was done with a leak of glutamate from a two-barrelled micropipette, the number of $5-\mathrm{HT}$ units recorded per tract was within the normal range (Table II), confirming that most of the 5-HT units were silent. After 7 days of treatment, the number of active 5-HT neurons per track had returned to normal values (Table II), but their mean firing rate was lower than in control animals. Figure 6 illustrates the time course of the progressive restoration of the firing rate of these neurons under prolonged zimelidine treatment.
Sensitivity of the 5-HT autoreceptor. 5-HT autoreceptors located on the somata of 5-HT neurons play a major role in regulating their rate of discharge (Aghajanian et al., 1975). We used LSD, a potent agonist of the 5-HT autoreceptor (Aghajanian and Haigler, 1974), to determine the sensitivity of these receptors following chronic zimelidine treatment. Figure 7 illustrates the response of two dorsal raphe units to the intravenous injections of 10 $\mu \mathrm{g} / \mathrm{kg}$ of LSD. In all control animals, this dose produced a complete cessation of firing within $60 \mathrm{sec}$. Following a 14-day treatment with zimelidine, the effect of the same dose of LSD was much smaller (control: $100 \pm 0 \%, n=5$ vs. zimelidine: $49 \pm 7 \%, n=5 ; p<0.001$ ). The $\mathrm{ED}_{50}$ of LSD in zimelidine-pretreated rats was increased 2.5 -fold based on the previously obtained $\mathrm{ED}_{50}$ of $4 \mu \mathrm{g} / \mathrm{kg}$ in naive rats (Blier and De Montigny, 1980).

This indicates that long-term zimelidine treatment leads to a desensitization of the 5-HT receptor. The 


\section{A}

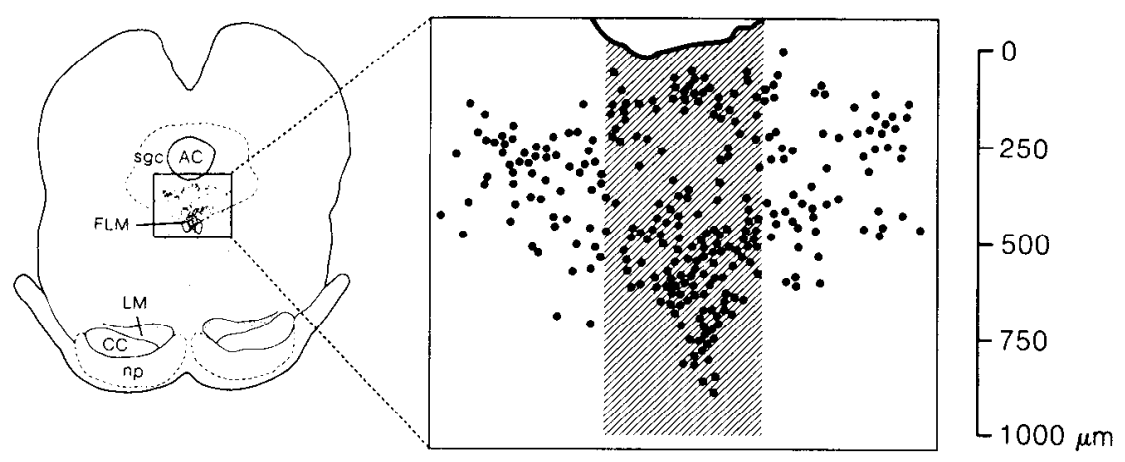

B
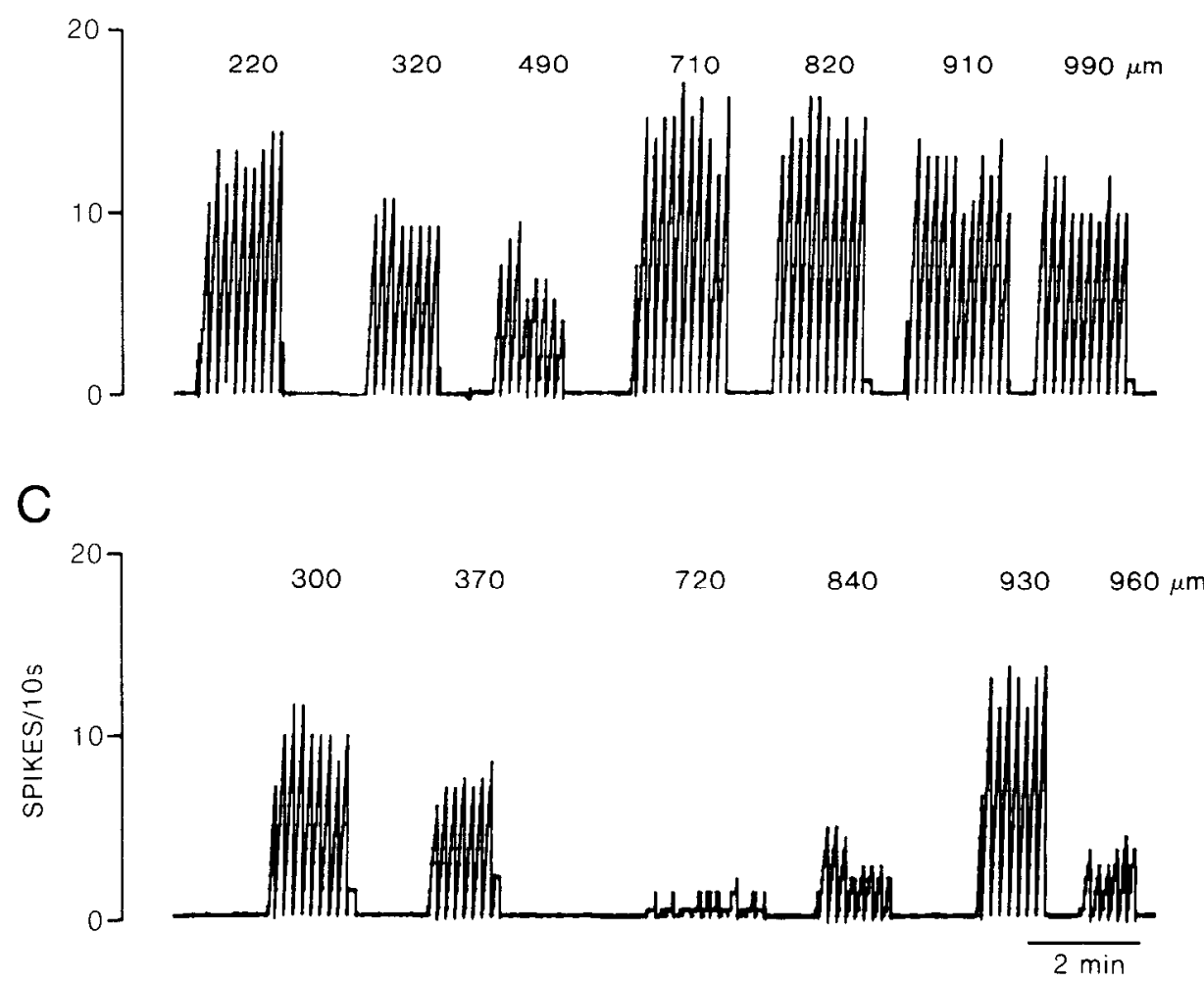

Figure 5. A, The area from which the 5-HT units were recorded (shaded area) is represented on the reproduction of a histological section prepared by radioautography following intraventricular injection of $\left[{ }^{3} \mathrm{H}\right] 5-\mathrm{HT}$. Each dot represents a 5-HT neuron. This section was kindly loaned to us by L. Descarries, K. C. Watkins, S. Garcia, and A. Beaudet (1982). $B$ and $C$, Integrated firing rate histograms of 5-HT neurons recorded during one electrode descent in the area delineated in $A$ from a control rat $(B)$ and a rat pretreated with zimelidine $(5 \mathrm{mg} / \mathrm{kg}$, i.p., q.d.) for 7 days $(C)$. The depth of recording for each neuron is indicated in micrometers from the Sylvius aqueduct.

prolonged exposure of the autoreceptor to an increased amount of 5-HT resulting from the sustained blockade of 5-HT reuptake by zimelidine probably leads to the desensitization of these receptors as witnessed by the decreased effectiveness of LSD.

\section{Discussion}

The present results show that chronic zimelidine administration fails to modify the responsiveness of hippocampal pyramidal neurons to microiontophoretically applied 5 -HT, whereas it enhances their response to the stimulation of the ascending 5-HT pathway. This differential effect of zimelidine might be explained by the location of the 5-HT terminals in the stratum radiatum (Azmitia and Segal, 1978). The stimulation-induced release of 5-HT from terminals would activate receptors located on remote dendrites, whereas the 5-HT ejected from the micropipette acts directly on the soma. Hence, the blockade of the uptake process can affect the response of these cells to the stimulation without modifying that to microiontophoretically applied 5-HT. This interpretation is in agreement with the unchanged respon- 


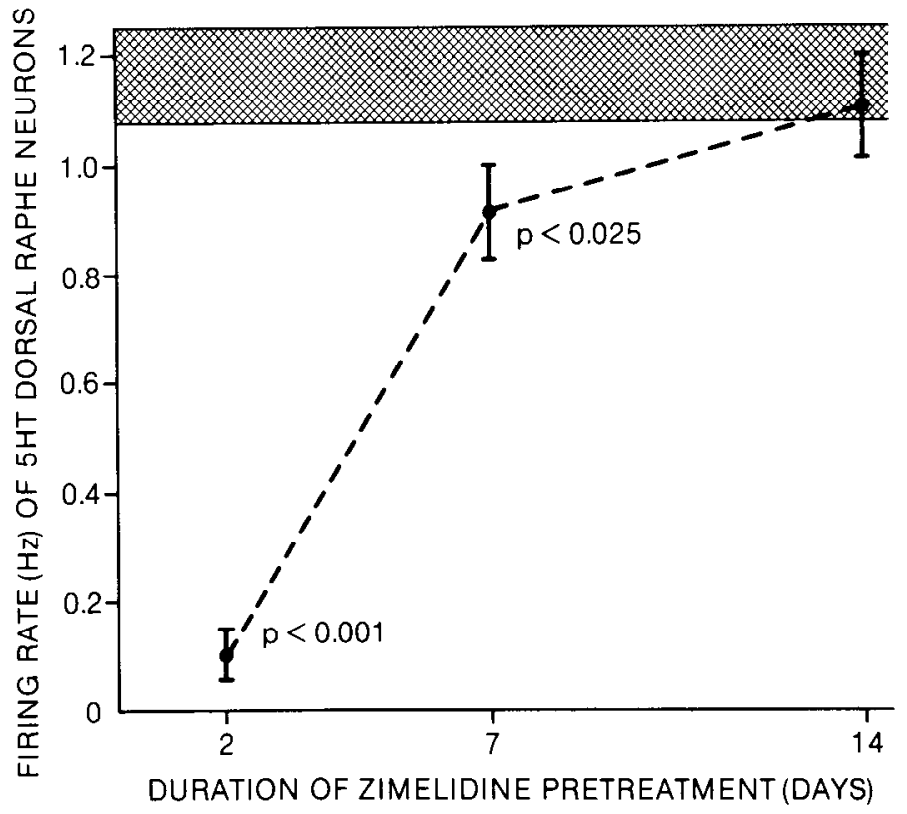

Figure 6. Graph showing the mean firing rate ( \pm SEM) of 5$\mathrm{HT}$ neurons recorded from the shaded area delineated in Figure $5 A$ in rats treated for 2,7 , and 14 days with zimelidine $(5 \mathrm{mg} /$ kg, i.p., q.d.). The shaded zone represents the range $(\mathrm{SEM} \times 2)$ of the firing frequency of 5-HT neurons recorded from the same area in control rats.

TABLE II

Number of 5-HT neurons recorded per 1-mm trajectory through the mesencephalic dorsal raphe in controls, 5,7-DHT-treated, and zimelidine-pretreated rats ${ }^{a}$

\begin{tabular}{lcc}
\hline & $\begin{array}{c}\text { No. of 5-HT Neurons } \\
\text { Recorded/Track }\end{array}$ & No. of Tracks \\
\hline Control & $4.2 \pm 0.6$ & 13 \\
$5,7-$ DHT & 0 & 8 \\
Zimelidine pretreated & & \\
2 days & $0.8 \pm 0.4^{b}$ & 15 \\
2 days (with glutamate) & $c$ & 5 \\
7 days & $4.2 \pm 1.0$ & 15 \\
14 days & $5.3 \pm 0.8$ & 17 \\
\hline
\end{tabular}

${ }^{\alpha}$ Zimelidine was administered at a daily dose of $5 \mathrm{mg} / \mathrm{kg}$, i.p., for the number of days indicated. Values are expressed as mean $\pm \mathrm{SEM}$.

${ }^{b} p<0.001$ (the Student's $t$ test, when compared with controls).

${ }^{c}$ A leak of glutamate was allowed through one barrel of a theta micropipette to activate silent units.

siveness of these neurons to 5 -HT applied by microiontophoresis following denervation with 5,7-DHT or acute reuptake blockade by fluoxetine (De Montigny et al., 1980).

Fuxe et al. (1979) have reported a decreased density of $\left[{ }^{3} \mathrm{H}\right] 5$-HT-binding sites and the induction of new low affinity binding sites in the hypothalamus following chronic zimelidine treatment. However, both these investigators and Ross et al. (1981) failed to detect any significant modification of $\left[{ }^{3} \mathrm{H}\right] 5-\mathrm{HT}$ high affinity binding sites or low affinity binding site induction in the cerebral cortex. The absence of decrement in the neuronal responsiveness to microiontophoretic application of 5-HT (present results and De Montigny et al., 1981a) indicates that there is no down-regulation of the postsynaptic 5$\mathrm{HT}$-sensitive effector mechanism in the hippocampus following chronic uptake blockade with zimelidine.

The enhanced response of hippocampal pyramidal cells to the electrical stimulation of the ascending 5-HT pathway following chronic zimelidine treatment must be attributed to the blockade of 5-HT uptake, since the responsiveness of the same neurons to direct microiontophoretic applications of 5-HT was not enhanced. Thus, in contrast with the postsynaptic sensitization induced by TCA drugs (De Montigny and Aghajanian, 1978; Gallagher and Bunney, 1979; Menkes et al., 1980; Wang and Aghajanian, 1980; De Montigny et al., 1981a; Menkes and Aghajanian, 1981), zimelidine would increase 5-HT neurotransmission via a presynaptic effect.

Sheard et al. (1972) and Scuvée-Moreau and Dresse (1979) have shown that acute 5-HT reuptake blockade reduces the firing rate of 5-HT neurons. In keeping with this observation we have previously reported that acute administration of zimelidine and norzimelidine depresses the rate of discharge of $5-\mathrm{HT}$ neurons $\left(\mathrm{ED}_{50}=1.1\right.$ and $0.8 \mathrm{mg} / \mathrm{kg}$, i.v., respectively) (De Montigny et al., 1981a). This effect of 5-HT reuptake blockers is probably due to an increased availability of the neurotransmitter at the autoreceptor site (Aghajanian, 1978). Thus, the markedly decreased activity of 5-HT raphe neurons at day 2 was expected, given the effectiveness of zimelidine and norzimelidine in blocking 5-H'T reuptake (Ross and Renyi, 1977 ) and the long half-life of norzimelidine (Brown et al., 1980). After 14 daily injections, the activity of 5-HT neurons is back within the normal range. At this point in time, the responsiveness to LSD, a potent agonist of the 5-HT autoreceptor (Aghajanian and Haigler, 1974), is reduced by 2- to 3-fold. Furthermore, Scuvée-Moreau (1981) has reported a decreased efficacy of acute zimelidine in depressing the firing rate of 5-HT neurons following chronic treatment with zimelidine. Consequently, the progressive restoration of $5-\mathrm{HT}$ neuronal activity under zimelidine treatment is attributable to the desensitization of the auto receptor. These results point to a major difference between the 5-HT autoreceptor and the postsynaptic 5-HT receptor: the former but not the latter desensitizes under long-term exposure to an increased amount of the neurotransmitter.

In contrast to zimelidine, chronic administration of femoxetine, chlorimipramine, or imipramine does not induce desensitization of the 5-HT autoreceptor (Blier and De Montigny, 1980; Scuvée-Moreau, 1981). Femoxetine and its metabolite, norfemoxetine, have a short half-life (Mengel and Lund, 1982); tertiary amine TCA drugs are rapidly demethylated into their secondary forms which are weak 5-HT uptake blockers (Ross and Renyi, 1975a, b; Nagy and Johansson, 1977). This suggests that a sustained blockade of $5-\mathrm{HT}$ reuptake is required for a desensitization of the 5-HT autoreceptor to occur.

In conclusion, the data presented here show that longterm zimelidine treatment enhances the synaptic efficacy of the 5-HT system via reuptake blockade. However, during the first few days of zimelidine administration the 


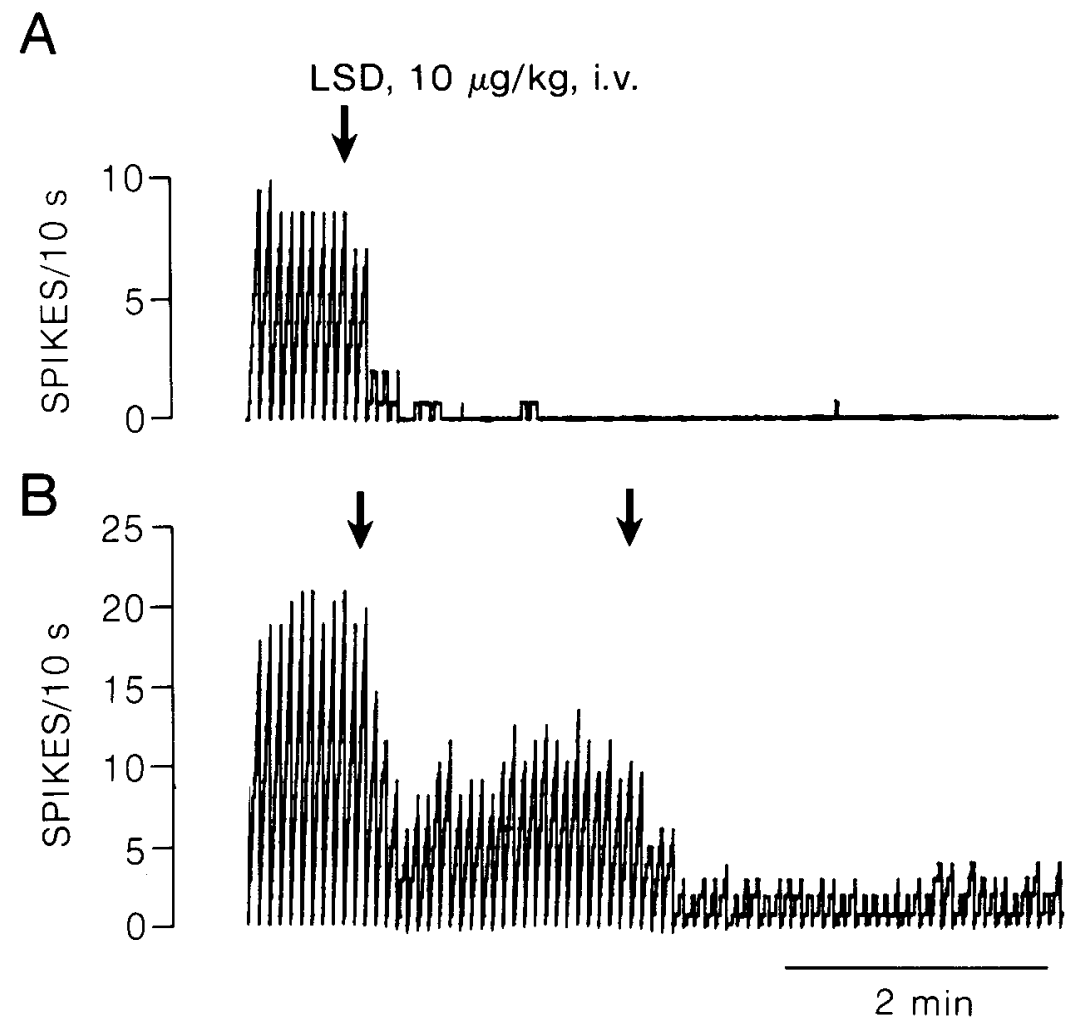

Figure 7. Integrated firing rate histograms of dorsal raphe 5-HT neurons showing the effect of intravenous administrations of $10 \mu \mathrm{g} / \mathrm{kg}$ of LSD (arrows) in a control rat $(A)$ and a zimelidine-pretreated rat $(5 \mathrm{mg} / \mathrm{kg}$, i.p., q.d. $\times 14$ days) $(B)$.

electrical activity of 5-HT neurons is markedly slowed down; after several days of treatment, it returns to normal levels. This sequence of events may well account for the delayed clinical action of zimelidine: the 5-HT reuptake blockade cannot result in an enhanced 5-HT neurotransmission until 5-HT neurons resume a normal electrical activity. This constitutes further evidence that enhancing 5-HT neurotransmission might have a therapeutic effect in major depression.

\section{References}

Aberg, A., and G. Holmberg (1979) Preliminary clinical test of zimelidine (H 102/09), a new 5-HT uptake inhibitor. Acta Psychiatr. Scand. 59: 45-58.

Aghajanian, G. K. (1978) Feedback regulation of central monoaminergic neurons: Evidence from single cell recording studies. In Essays in Neurochemistry and Neuropharmacology, M. B. H. Youdim, W. Lovenberg, D. F. Sharman, and J. R. Lagnado, eds., Vol. 3, pp. 1-32, John Wiley and Sons, New York.

Aghajanian, G. K. and H. J. Haigler (1974) Mode of action of LSD on serotonergic neurons. Adv. Biochem. Psychopharmacol. 10: 167-178.

Aghajanian, G. K., H. J. Haigler, and J. L. Bennett (1975) Amine receptors in CNS. III. 5-Hydroxytryptamine in brain. In Handbook of Psychopharmacology, L. L. Iversen, S. D. Iversen, and S. M. Snyder, eds., Vol. 6, pp. 63-76, Plenum Publishing Corp., New York.

Andén, N. E., A. Dahlström, K. Fuxe, K. Larsson, L. Olson, and U. Ungerstedt (1966) Ascending monoamine neurons to the telencephalon and diencephalon. Acta Physiol. Scand. 67: 313-326.

Azmitia, E. C., and M. Segal (1978) An autoradiographic analysis of the differential ascending projections of the dorsal and median raphe in the rat. J. Comp. Neurol. 179: 641-668.

Baumgarten, H. G., and L. Lachenmayer (1972) 5,7-Dihydroxytryptamine: Improvement in chemical lesioning of indoleamine neurons in the mammalian brain. Z. Zellforsch. 135: 399-414.

Bjorklund, A., H. G. Baumgarten, and A. Rensch (1975) 5,7Dihydroxytryptamine: Improvement of its selectivity for serotonin neurons in the CNS by pretreatment with desipramine. J. Neurochem. 24: 833-835.

Blier, P., and C. De Montigny (1980) Effect of tricyclic antidepressant treatment on the serotoninergic autoreceptor: A microiontophoretic study in the rat. Naunyn-Schmiedebergs Arch. Pharmacol. 314: 123-128.

Brown, D., D. H. T. Scott, D. B. Scott, M. Meyer, D. Westerlund, and F. Lundstrom (1980) Pharmacokinetics of zimelidine. Eur. J. Clin. Pharmacol. 17: 111-116.

Coppen, A., V. A. Ramo Rao, C. Swade, and K. Wood (1979) Zimelidine: A therapeutic and pharmacokinctic study in depression. Psychopharmacology 63: 199-200.

Costain, D. W., A. R. Green, and D. G. Grahame-Smith (1979) Enhanced 5-hydroxytryptamine-mediated behavioural responses in rats following repeated electroconvulsive shock: Relevance to the mechanism of the antidepressive effect of electroconvulsive therapy. Psychopharmacology 61: 167-170.

De Montigny, C. (1980) Electroconvulsive shock treatment increases responsiveness of forebrain neurons to serotonin: A microiontophoretic study in the rat. Soc. Neurosci. Abstr. 6: 152. 
De Montigny, C., and G. K. Aghajanian (1977) Preferential action of 5-methoxytryptamine and 5-methoxydimethyltryptamine on presynaptic serotonin receptors: A comparative iontophoretic study with LSD and 5-HT. Neuropharmacology 16: 811-818.

De Montigny, C., and G. K. Aghajanian (1978) Tricyclic antidepressants: Long-term treatment increases responsivity of rat forebrain neurons to serotonin. Science 202: 1303-1306.

De Montigny, C., R. Wang, T. Reader, and G. K. Aghajanian (1980) Monoaminergic denervation of the rat hippocampus: Microiontophoretic studies on pre- and postsynaptic supersensitivity to norepinephrine and serotonin. Brain Res. 200: 363-376.

De Montigny, C., P. Blier, G. Caillé, and E. Kouassi (1981a) Pre- and postsynaptic effects of zimelidine and norzimelidine on the serotoninergic system: Single cell studies in the rat. Acta Psychiatr. Scand. 63(Suppl. 290): 79-90.

De Montigny, C., F. Grunberg, A. Mayer and J. P. Deschesne (1981b) Lithium induces rapid relief of depression in tricyclic antidepressant drug non-responders. Br. J. Psychiatry 138: 252-256.

Descarries, L., K. C. Watkins, S. Garcia, and A. Beaudet (1982) The serotonin neurons in nucleus raphe dorsalis of adult rat: A light and electron microscope radioautographic study. J. Comp. Neurol. 207: 239-254.

Evans, J. P. M., D. G. Grahame-Smith, A. R. Green, and A. F. C. Tordoff (1976) Electroconvulsive shock increases the behavioural responses of rats to brain 5-hydroxytryptamine accumulation and central nervous system stimulant drugs. Br. J. Pharmacol. 56: 193-199.

Fuxe, K., S. -O. Ögren, and L. F. Agnati (1979) The effects of chronic treatment with the 5-hydroxytryptamine (5-HT) uptake blocker zimelidine on central 5-HT mechanisms. Evidence for the induction of a low affinity binding site for 5HT. Neurosci. Lett. 13: 307-319.

Gallager, D. W., and W. E. Bunney, Jr. (1979) Failure of chronic lithium treatment to block tricyclic antidepressant-induced 5-HT supersensitivity. Naunyn-Schmiedegers Arch. Pharmacol. 307: 129-133.

Gershon, S., A. Georgotas, R. Newton, and D. Bush (1982) Clinical evaluation of two new antidepressants. Adv. Biochem. Psychopharmacol. 32: 57-68.

Gerson, S., and R. J. Baldessarini (1975) Selective destruction of serotonin terminals in rat forebrain by high doses of 5,7dihydroxytryptamine. Brain Res. 85: 140-145.

Grahame-Smith, D. G., and A. R. Green (1974) The role of brain 5-hydroxytryptamine in the hyperactivity produced in rats by lithium and monoamine oxidase inhibition. $\mathrm{Br}$. J. Pharmacol. 52: 19-26.

Grahame-Smith, D. G., A. R. Green, and D. W. Costain (1978) Mechanism of the antidepressant action of electroconvulsive therapy. Lancet 1: 254-256.

Green, A. R., D. J. Heal, and D. G. Grahame-Smith (1977) Further observations on the effect of repeated electroconvulsive shock on the behavioural responses of rats produced by increases in the functional activity of brain 5-hydroxytryptamine and dopamine. Psychopharmacology 5: 195-200.

Haigler, H. J., and G. K. Aghajanian (1974) Lysergic acid diethylamide and serotonin: A comparison of effects on serotonergic neurons and neurons receiving a serotonergic input. J. Pharmacol. Exp. Ther. 188: 688-699.

Heninger, G. R., and D. S. Charney (1982) Lithium potentiation of antidepressant treatment. Abstract NR66, American Psychiatric Association, Washington, D. C.

Kandel, E. R., and W. A. Spencer (1961) Electrophysiology of hippocampal neurons. II. After-potentials and repetitive firing. J. Neurophysiol. 24: 243-259.

Köhler, C. (1982) On the serotoninergic innervation of the hippocampal region: An analysis employing immunocytochemistry and retrograde fluorescent tracing in the rat brain.
In Cylochemical Methods in Neuroanatomy, V. Chan-Palay and S. L. Palay, eds., pp 387-405, Alan R. Liss, Inc., New York.

Köhler, C., and H. Steinbusch (1982) Identification of serotonin and non-serotonin-containing neurons of the mid-brain raphe projecting to the entorhinal area and the hippocampal formation. A combined immunohistochemical and fluorescent retrograde tracing study in the rat brain. Neuroscience 7 : 951-975.

König, J. F. R., and R. A. Klippel (1963) The Rat Brain: A Stereotaxic Atlas of the Forebrain and Lower Parts of the Brainstem. Williams \& Wilkins, Baltimore.

Lapin, J. P., and G. F. Oxenkrüg (1969) Intensification of the central serotonergic processes as a possible determinant of the thymoleptic effect. Lancet 1: 132-136.

Mengel, $H$., and I. Lund (1982) Kinetics and effects of femoxitine and norfemoxitine in man. Coll. Int. Neuro-Psychopharmacol., 13: 78.

Menkes, D. B., and G. K. Aghajanian (1981) $\alpha$-1 Adrenoceptormediated responses in the lateral geniculate nucleus are enhanced by chronic antidepressant treatment. Eur. J. Pharmacol. 74: 27-35.

Menkes, D. B., G. K. Aghajanian, and R. B. McCall (1980) Chronic antidepressant treatment enhances $\alpha$-adrenergic and serotoninergic responses in the facial nucleus. Life Sci. 27: 45-55.

Montgomery, S. A., S. J. Rani, R. McAuley, D. Roy, and D. B. Montgomery (1981) The antidepressant efficacy of zimelidine and maprotiline. Acta Psychiatr. Scand. 63(Suppl. 290): 219224.

Nagy, A., and R. Johansson (1977) The demethylation of imipramine and clomipramine as apparent from their plasma kinetics. Psychopharmacology 54: 125-131.

Ross, S. B., and A. L. Renyi (1975a) Tricyclic antidepressant agents. I. Comparison of the inhibition of the uptake of ${ }^{3} \mathrm{H}$ noradrenaline and ${ }^{14} \mathrm{C}$-5-hydroxytryptamine in slices and crude synaptosome preparations of midbrain-hypothalamus region of the rat brain. Acta Pharmacol. Toxicol. 36: 382-394.

Ross, S. B., and A. L. Renyi (1975b) Tricyclic antidepressant agents. II. Effect of oral administration of the uptake of ${ }^{3} \mathrm{H}$ noradrenaline and ${ }^{14} \mathrm{C}-5$-hydroxytryptamine in slices of the midbrain-hypothalamus region of the rat. Acta Pharmacol. Toxicol. 36: 395-408.

Ross, S. B., and A. L. Renyi (1977) Inhibition of the neuronal uptake of 5-hydroxytryptamine and noradrenaline in rat brain by (Z) - and (E)-3-(4-bromophenyl)-N,N-dimethyl-3-(3pyridyl)allylamines and their secondary analogues. Neuropharmacology 16: 57-63.

Ross, S. B., H. Hall, A. L. Renyi, and D. Westerlund (1981) Effects of zimelidine on serotoninergic and noradrenergic neurons after repeated administration in the rat. Psychopharmacology 72: 219-225.

Scuvée-Moreau, J. (1981) Contribution expérimentale à l'étude du mode d'action des substances antidépressives. D.Sc. thesis, Université de Liège, Liège, Belgium.

Scuvée-Moreau, J., and A. R. Dresse (1979) Effect of various antidepressant drugs on the spontaneous firing rate of locus coeruleus and dorsal raphe neurons of the rat. Eur. J. Pharmacol. 57: 219-225.

Sheard, M. H., A. Zolovick, and G. K. Aghajanian (1972) Raphe neurons: Effect of tricyclic antidepressant drugs. Brain Res 43: $690-694$.

Shopsin, B., S. Gershon, M. Goldstein, F. Friedman, and S. Wilk (1975) Use of synthesis inhibitors in defining a role for biogenic amines during imipramine treatment in depressed patients. Commun. Psychopharmacol. 1: 239-249.

Wang, R. Y., and G. K. Aghajanian (1980) Enhanced responsivity of amygdaloid neurons to serotonin and norepinephrine after chronic antidepressant treatment. Commun. Psychopharmacol. 4: 83-90. 